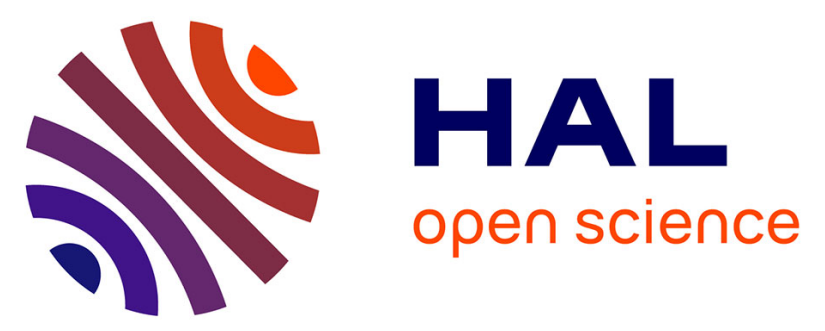

\title{
A comparison of the acidity and the complexing ability of (o-hydroxyphenyl) bis-and (o-hydroxyphenyl) mono-methylenephosphonic acids towards lanthanide(III) ions
}

\author{
Embarek Bentouhami, Gilles M Bouet, Mustayeen A Khan
}

\section{To cite this version:}

Embarek Bentouhami, Gilles M Bouet, Mustayeen A Khan. A comparison of the acidity and the complexing ability of (o-hydroxyphenyl) bis-and (o-hydroxyphenyl) mono-methylenephosphonic acids towards lanthanide(III) ions. Talanta, 2002, 57 (3), pp.545-554. 10.1016/S0039-9140(02)00056-5 . hal-03221381

\section{HAL Id: hal-03221381 \\ https://univ-angers.hal.science/hal-03221381}

Submitted on 11 May 2021

HAL is a multi-disciplinary open access archive for the deposit and dissemination of scientific research documents, whether they are published or not. The documents may come from teaching and research institutions in France or abroad, or from public or private research centers.
L'archive ouverte pluridisciplinaire HAL, est destinée au dépôt et à la diffusion de documents scientifiques de niveau recherche, publiés ou non, émanant des établissements d'enseignement et de recherche français ou étrangers, des laboratoires publics ou privés. 


\title{
A comparison of the acidity and the complexing ability of (o-hydroxyphenyl) bis- and (o-hydroxyphenyl) mono-methylenephosphonic acids towards lanthanide(III) ions
}

\author{
Embarek Bentouhami, Gilles M. Bouet, Mustayeen A. Khan * \\ Laboratoire de Chimie de Coordination, Facultè de Pharmacie, 16 Boulevard Daviers, F-49045 Angers, Cedex 01, France
}

Received 18 September 2001; received in revised form 9 January 2002; accepted 18 February 2002

\begin{abstract}
The characterization of the acid-base properties of a family of three phenoldimethylenephosphonic acids differently substituted by auxo- or chromophoric groups was studied. These ligands may be considered as pentaacids. Their $\mathrm{p} K_{\mathrm{a}}$ were determined in aqueous solution at $25{ }^{\circ} \mathrm{C}$ and constant ionic strength $0.1 \mathrm{~mol} \mathrm{dm}^{-3}$ by potentiometry and UV-visible spectrophotometry. Eventually, the complexing power of these molecules with lanthanide cations, $\mathrm{Ce}^{3+}, \mathrm{Pr}^{3+}, \mathrm{Nd}^{3+}, \mathrm{Sm}^{3+}$ and $\mathrm{Eu}^{3+}$, was studied keeping in view the possible application to the treatment of radioactive liquid waste. The number, the nature of the species in solution, their stability constants and their individual electronic spectra as restored by computation have been determined. In all cases, complexes of 1:1 stoichiometry accompanied by hydroxy and protonated species are postulated. The comparison of tri- and pentaacids confirms that the acids having the methyl group at the para position with respect to the phenolic $\mathrm{OH}$, have the highest complexing power. (C) 2002 Elsevier Science B.V. All rights reserved.
\end{abstract}

Keywords: Lanthanide(III) complexes; Phenol methylenephosphonic acids; Protonation constants; Stability constants

\section{Introduction}

A large number of phosphonic compounds have already been examined with respect to their complexing properties and their suitability as extractants in industrial applications [1-3].

* Corresponding author. Tel.: + 33-2-41-226739; fax: + 332-41-486733.

E-mail address: mustayeen.khan@univ-angers.fr (M.A. Khan).
The stability constants of the complexes of $\mathrm{Ln}^{3+}$ with some ligands have been reported. Tikhinova studied the system $N, N^{\prime}$-di-(carboxymethyl) ethylenediamine bis-methylphosphonic acid (EDPA) towards $\mathrm{Y}^{3+}, \mathrm{Yb}^{3+}$ and $\mathrm{Ce}^{3+}$ [4]. The author reported higher stability of the complexes with respect to carboxylic homologues. Tereshin et al. [5] studied the complexation of $\mathrm{Y}^{3+}$ with nitrilotrimethylphosphonic acid and postulated two types of complexes, viz. $\mathrm{YHL}^{2-}$ and $\mathrm{YH}_{2} \mathrm{~L}^{-}$. Suran et al. [6], on the other hand, 
retained a model with four complexes, $\mathrm{MLOH}$, ML, MLH and $\mathrm{MLH}_{2}$. Sujatha and co-workers [7] have also reported the extraction of $\mathrm{Ce}(\mathrm{III})$
As comparison has been made with (o-hydroxyphenyl) mono-methylenephosphonic acids in the discussion section, their structure scheme $(\mathbf{1 a}-\mathbf{e})$ is presented here as well 2 .

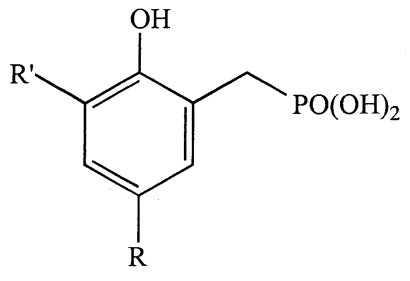
1a: $R=H$ and $R^{\prime}=H$
1b: $\mathrm{PO}(\mathrm{OH})_{2}$ in para, $\mathrm{R}$ and $\mathrm{R}^{\prime}$ in ortho $=\mathrm{H}$
1c: $\mathrm{R}=\mathrm{NO}_{2}$ and $\mathrm{R}^{\prime}=\mathrm{H}$
1d: $\mathrm{R}=\mathrm{CH}_{3}$ and $\mathrm{R}^{\prime}=\mathrm{NO}_{2}$
1e: $\mathrm{R}=\mathrm{NO}_{2}$ and $\mathrm{R}^{\prime}=\mathrm{CH}_{3}$

and $\mathrm{Nd}(\mathrm{III})$ by 2-ethylhexyl mono-2 ethylhexylester phosphonic acid (EHEHPA) in the presence of a second complexing agent which improves the separation factor amongst the lanthanides. Wagener et al. [8] have presented an interesting graph relative to complexes of lanthanides with diaminetetramethylene phosphonate (EDTMP). This graph of stability constants shows a maximum for Gd(III). Recently, Benghanem et al. [9] have reported the acid-base properties of a series of phenol methylenephosphonic acids. A recent $\mathrm{pH}$-metric and spectrophotometric studies on the acidity of a family of ( $o$-hydroxyphenyl) mono-methylenephosphonic acids (triacid series $\mathrm{LH}_{3}$ ) and the stability of their lanthanide (III) complexes has been submitted by our laboratory [10] and the work has now been extended to pentaacids.

The present paper describes a detailed potentiometric and UV-visible spectrophoto-metric study of the proton dissociation of the bismethylenephosphonic acids (pentaacid series $\mathrm{LH}_{5}$ ) $\mathbf{2 a}-\mathbf{c}$, as given in the scheme below, and of their lanthanide (III) complexes. The calculations were done with a method using numerical and chemical criteria for the representation of the model under investigation 1 .<smiles></smiles>

2a: $\mathrm{R}=\mathrm{CH}_{3}$

2b: $\mathrm{R}=\mathrm{NO}_{2}$

2c: $\mathrm{R}=\mathrm{Cl}$

\section{Experimental section}

\subsection{Reagents}

All the compounds were synthesized as described by Böhmer et al. [11] and their purity was controlled by microanalysis: Anal. Calc. for $\mathbf{2 a}$ : C, 34.12; H, 5.82. Found: C, 34.37; H, 5.58\%. Anal. Calc. for 2b: C, 29.40; H, 3.39; N, 4.28. Found: C, 28.50; H, 3.73; N, 3.99\%. Anal. Calc. for 2c: C, 28.91; H, 4.69. Found: C, 29.08; H, 4.40\%.

Ligand solutions were kept away from light, in order to avoid degradation, and were used, at the latest, 5 days after their preparation. The lanthanide (III) chlorides were commercial products p.a. (Janssen for $\mathrm{Ce}$, $\mathrm{Pr}$ and $\mathrm{Eu}$, Aldrich for $\mathrm{Nd}$ and Ventron for Sm). Solutions of $0.1 \mathrm{~mol} \mathrm{dm}^{-3}$ $\mathrm{Na}\left(\mathrm{ClO}_{4}\right) \cdot 6 \mathrm{H}_{2} \mathrm{O}$ (Fluka p.a.) and $1 \mathrm{~mol} \mathrm{dm}^{-3}$ $\mathrm{NaOH}$ (Merck) were prepared with doubly distilled and boiled water. The $\mathrm{pH}$ values of the solutions were adjusted by simple addition of acid $\left(\mathrm{HClO}_{4}\right)$ or of base $(\mathrm{NaOH})$ and controlled with a precision $\mathrm{pH}$-meter. The solution of $\mathrm{Na}\left(\mathrm{ClO}_{4}\right)$ was added to the medium so that the ionic strength remains constant and equal to $0.1 \mathrm{~mol}$ $\mathrm{dm}^{-3}$. Stock solutions of metals, $10^{-2} \mathrm{~mol}$ 
$\mathrm{dm}^{-3}$, were prepared by mixing the solid metal (III) chlorides with the solvent; these solutions were standardized with EDTA [12] at $\mathrm{pH}$ 6, using xylenol orange as indicator. The final analytical concentration of metal was $10^{-2}$ or $10^{-3} \mathrm{~mol}$ $\mathrm{dm}^{-3}$ for potentiometric study and $10^{-4} \mathrm{~mol}$ $\mathrm{dm}^{-3}$ for measurements in $\mathrm{UV}$-visible. $\mathrm{NaClO}_{4}$, $0.1 \mathrm{~mol} \mathrm{dm}^{-3}$ was the spectrophotometric reference solution. The final solutions of metal and ligand were prepared just before the measurements.

\subsection{Potentiometric measurements}

The potentiometric investigations of acid-base and metal-binding equilibria were carried out at $25.0 \pm 0.1{ }^{\circ} \mathrm{C}$ and ionic strength $0.1 \mathrm{~mol} \mathrm{dm}^{-3}$ $\left(\mathrm{NaClO}_{4}\right)$. The complexation was studied in aqueous solution with equal analytical concentrations of the ligand $C_{\mathrm{L}}$ and the cation $C_{\mathrm{M}}\left(10^{-2}\right.$ mol $\mathrm{dm}^{-3}$ with $\mathbf{2 a}$ and $\mathbf{2 b}$ and $10^{-3} \mathrm{~mol} \mathrm{dm}^{-3}$ with 2c). All experiments were performed according to the method previously described [10].

\subsection{Spectrophotometric measurements}

The spectra, in the range of $200-550 \mathrm{~nm}$, were recorded on a Shimadzu UV 2101 PC spectrophotometer equipped with a thermostat and matched $10 \mathrm{~mm}$ quartz cell. The absorption variations of acid-base and metal-binding equilibria were carried out at $25.0 \pm 0.1{ }^{\circ} \mathrm{C}$ and the ionic strength of solutions was maintained constant, fixed at 0.1 mol dm ${ }^{-3}$, with the help of the supporting electrolyte $\mathrm{NaClO}_{4}$. The concentration of the ligands should not exceed $10^{-3} \mathrm{~mol} \mathrm{dm}{ }^{-3}$ to guarantee accurate and confident absorbance values between 0.2 and 2.0. All investigations in the presence of metal ions were carried out at a 1:1 molar ratio of metal ion to ligand. No determination could be done with higher molar ratios due to precipitation phenomena. Therefore, the analytical concentration of the metal and ligand was fixed at $10^{-4}$ mol $\mathrm{dm}^{-3}$. Under these experimental conditions, only the formation of the mononuclear complexes was envisaged. The ligand solutions are stable for a few days, however, the spectra were run immediately after mixing the reagents.

\subsection{Calculation of equilibrium constants}

All the constants and their equations corresponding to the different equilibria involved in this study are described in our publication [10].

\subsubsection{Potentiometric data}

Approximate values of the stepwise protonation constants $K_{i}$, the overall protonation constants $\beta_{01 z}$, and the overall stability constants $\beta_{x y z}$ of the complexes were computed. The treatment of the potentiometric data was done using several titrations, each including not less than 150 points, by fitting to the Sirko [13] and/or Superquad [14] programs.

\subsubsection{Spectrophotometric data}

Computational treatment of the set of spectra, obtained for different $\mathrm{pH}$ values, results in the dissociation constants of the ligands ( $\mathrm{p} K_{\mathrm{a}}$ values) and overall stability constants of the complexes $\left(\beta_{x y z}\right)$ and in the individual electronic spectra for all species involved. These $\mathrm{p} K_{\mathrm{a}}$ values are compared with the potentiometric results reported previously $[11,15]$. The numerical treatment concerns a large set of absorbance values covering the whole investigated wavelength range (21 solutions, 32 wavelengths). The whole set of spectrophotometric data was analyzed using the multiwavelength program Sirko S [13] and/or Letagrop-Spefo [16] which refines the overall stability constant $\beta_{x y z}$ of the complexes. The apparent overall stability constants $\beta_{x y z}$ of the complexes, correspond to the following equilibrium:

$$
\begin{aligned}
& x \mathrm{M}^{m+}+y \mathrm{~L}^{n-}+z \mathrm{H}^{+} \rightleftharpoons \mathrm{M}_{x} \mathrm{~L}_{y} \mathrm{H}_{z}^{(x m-y n+z)^{+}} \\
& \beta_{x y z}=\frac{\left[\mathrm{M}_{x} \mathrm{~L}_{y} \mathrm{H}_{z}^{\left.(x m-y n+z)^{+}\right]}\right.}{\left[\mathrm{M}^{m+}\right]^{x}\left[\mathrm{~L}^{n-}\right]^{y}\left[\mathrm{H}^{+}\right]^{z}}
\end{aligned}
$$

where $x$ pertains to metal $(\mathrm{M}), y$ is for ligand (L) and $z$ for proton $(\mathrm{H})$. In the case of hydroxo species, $z$ is negative.

The calculated values are indicated with $99 \%$ confidence interval $( \pm 3 \sigma)$. The protonation constants $\beta_{01 z}$ of the ligands were kept constant during the refinement procedure of the stability constants, as well as the formation constants or $\beta_{01 z}$ of hydroxo species, in this case $z$ is negative. 


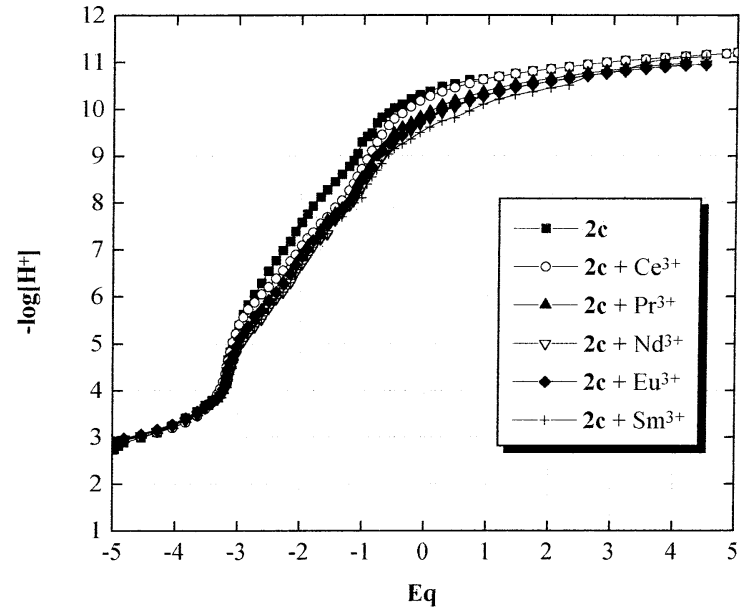

Fig. 1. Titration curves for $\mathbf{2 c}$ and $\mathrm{Ln}(\mathrm{III})-\mathbf{2 c}$ complexes in aqueous solution $\left(C_{\mathrm{L}}=C_{\mathrm{M}}=10^{-3} \mathrm{~mol} \mathrm{dm}^{-3}, 25^{\circ} \mathrm{C}, I=0.1\right.$ mol dm $\left.{ }^{-3} \mathrm{NaClO}_{4}\right)$.

\section{Results}

The quantitative interpretation of potentiometric and spectrophotometric data was carried out on molecules $\mathbf{2 a}, \mathbf{2 b}, \mathbf{2 c}$. The results of ligand $\mathbf{2 b}$, which contains the chromophore group $\mathrm{NO}_{2}$ on the aromatic ring were exploited spectrophotometrically. This was not possible with molecules 2a and 2c because of their feeble spectral variation with respect to $\mathrm{pH}$.

\subsection{Potentiometry}

Fig. 1 shows, as an example, the protonation curve of ligand $2 \mathbf{c}$ and the titration curves in the presence of various lanthanides $\left(2 \mathbf{c}+\mathrm{Ln}^{3+}\right.$, $C_{\mathrm{M}}=C_{\mathrm{L}}=10^{-3} \mathrm{~mol} \mathrm{dm}^{-3}$ ).

\subsubsection{Acid-base equilibrium}

The five $\mathrm{p} K_{\mathrm{a}}$ values determined are in good agreement with those previously obtained by Vogt et al. [1], and Ameziane and co-workers [15], especially if we take into account the differences in experimental conditions such as ionic strength and temperature (Table 1). For the three ligands the weaker acidity is attributed to the phenolic $\mathrm{OH}$ group and the corresponding higher values of $\mathrm{p} K_{\mathrm{a}}$ can, as already pointed out, be explained by intramolecular $\mathrm{H}$ bonds between the $\mathrm{POH}$ groups and the phenolic $\mathrm{OH}$.

\subsubsection{Complexation studies}

The titration curves of the ligand $\mathbf{2 c}$ in the presence of metal cations (Fig. 1) show that before the first equivalent point, all the curves are superimposed which means that no complexation occurs below pH 3.5 under present experimental

Table 1

The five $\mathrm{p} K_{\mathrm{a}}$ values determined by Sirko-P program and a comparison with values reported by other authors

\begin{tabular}{|c|c|c|c|c|c|}
\hline Ligand & $\mathrm{p} K_{\mathrm{a} 1}$ & $\mathrm{p} K_{\mathrm{a} 2}$ & $\mathrm{p} K_{\mathrm{a} 3}$ & $\mathrm{p} K_{\mathrm{a} 4}$ & $\mathrm{p} K_{\mathrm{a} 5}$ \\
\hline \multirow[t]{5}{*}{$2 \mathbf{a}$} & $1.4 \pm 0.4$ & $2.8 \pm 0.5$ & $6.6 \pm 0.4$ & $8.1 \pm 0.4$ & $11.4 \pm 0.2$ \\
\hline & & $2.8 \pm 0.2^{\mathrm{a}}$ & $6.6 \pm 0.2^{\mathrm{a}}$ & $8.2 \pm 0.1^{\mathrm{a}}$ & $11.6 \pm 0.1^{\mathrm{a}}$ \\
\hline & $1.5^{\mathrm{b}}$ & $2.5^{\mathrm{b}}$ & $6.5^{\mathrm{b}}$ & $8.3^{\mathrm{b}}$ & $11.8^{\mathrm{b}}$ \\
\hline & $1.6^{\mathrm{c}}$ & $2.3^{\mathrm{c}}$ & $6.4^{\mathrm{c}}$ & $8.1^{\mathrm{c}}$ & $11.8^{\mathrm{c}}$ \\
\hline & $1.2 \pm 0.1^{\mathrm{d}}$ & $2.2 \pm 0.1^{\mathrm{d}}$ & $6.2 \pm 0.1^{\mathrm{d}}$ & $9.0 \pm .0 .1^{\mathrm{d}}$ & $12.8 \pm 0.1^{\mathrm{d}}$ \\
\hline \multirow[t]{3}{*}{$2 b$} & $1.7 \pm 0.8$ & $2.2 \pm 0.6$ & $5.9 \pm 0.4$ & $7.8 \pm 0.5$ & $10.2 \pm 0.4$ \\
\hline & $1.01^{\mathrm{b}}$ & $2 . \overline{2^{\mathrm{b}}}$ & $5 . \overline{9^{b}}$ & $7 . \overline{9} 0^{\mathrm{b}}$ & $10 . \overline{5}^{\mathrm{b}}$ \\
\hline & $1.6^{\mathrm{c}}$ & $2.0^{\mathrm{c}}$ & $5.8^{\mathrm{c}}$ & $7.8^{\mathrm{c}}$ & $10.3^{\mathrm{c}}$ \\
\hline \multirow[t]{4}{*}{$2 \mathrm{c}$} & $1.2 \pm 0.8$ & $2.4 \pm 0.8$ & $5.93 \pm 0.52$ & $7.84 \pm 0.35$ & $11.74 \pm 0.28$ \\
\hline & & $2.5 \pm 0.1^{\mathrm{a}}$ & $6.0 \pm 0.1^{\mathrm{a}}$ & $7.9 \pm 0.1^{\mathrm{a}}$ & $11.7 \pm 0.1^{\mathrm{a}}$ \\
\hline & $1.5^{\mathrm{b}}$ & $2.3^{\mathrm{b}}$ & $6.3^{\mathrm{b}}$ & $8.1^{\mathrm{b}}$ & $11.9^{\mathrm{b}}$ \\
\hline & $1.7^{\mathrm{c}}$ & $2.1^{\mathrm{c}}$ & $6.1^{\mathrm{c}}$ & $7.9^{\mathrm{c}}$ & $11.7^{\mathrm{c}}$ \\
\hline
\end{tabular}

${ }^{\text {a }}$ Values determined by authors with Superquad program.

${ }^{\mathrm{b}}$ Values determined by Vogt and co-workers, method 1, [11].

${ }^{c}$ Values determined by Vogt and co-workers, method 2, [11].

${ }^{\mathrm{d}}$ Values determined by Ameziane and co-workers, [15]. 
Table 2

Values of $\log \beta_{11 z} \pm \sigma_{N-1}(N=8)$ determined by Sirko $\mathrm{P}$ program for the complexes formed with $\mathrm{Ln}^{3+}$ in water from potentiometric data $\left(25^{\circ} \mathrm{C}, I=0.1 \mathrm{~mol} \mathrm{dm}^{-3} \mathrm{NaClO}_{4}\right)$

\begin{tabular}{|c|c|c|c|c|c|c|c|c|c|}
\hline Ligand & Cation & $\log \beta_{110}$ & $\log \beta_{111}$ & $\log \beta_{112}$ & $\log \beta_{113}$ & $\log \beta_{11-1}$ & $\log \beta_{11-2}$ & $\mathrm{pH}$ range & $R_{\mathrm{f}}$ \\
\hline $2 \mathbf{a}$ & $\mathrm{Ce}(\mathrm{III})$ & $11.36 \pm 0.09$ & $20.16 \pm 0.08$ & $26.54 \pm 0.08$ & $29.4 \pm 0.9$ & $0.5 \pm 0.1$ & $-12.0 \pm 0.4$ & $1.89-10.95$ & 2.0 \\
\hline $\begin{array}{l}C_{\mathrm{L}} \\
=10^{-2 \mathrm{a}}\end{array}$ & $\operatorname{Pr}(\mathrm{III})$ & $12.0 \pm 0.3$ & $20.7 \pm 0.3$ & $26.9 \pm 0.3$ & $29.6 \pm 0.5$ & $1.2 \pm 0.3$ & $-11.9 \pm 0.4$ & $1.83-10.93$ & 2.1 \\
\hline \multirow{3}{*}{$\begin{array}{l}C_{\mathrm{M}} \\
=10^{-2}\end{array}$} & $\mathrm{Nd}(\mathrm{III})$ & $12.0 \pm 0.3$ & $20.9 \pm 0.3$ & $27.3 \pm 0.3$ & $30.1 \pm 0.4$ & $1.2 \pm 0.3$ & $-11.3 \pm 0.4$ & $1.88-10.58$ & 2.1 \\
\hline & $\mathrm{Sm}$ (III) & $12.8 \pm 0.4$ & $21.3 \pm 0.4$ & $27.3 \pm 0.4$ & $30.1 \pm 0.5$ & $2.2 \pm 0.4$ & $-9.7 \pm 0.5$ & $1.79-10.91$ & 2.8 \\
\hline & $\mathrm{Eu}(\mathrm{III})$ & $11.97 \pm 0.08$ & $20.84 \pm 0.07$ & $26.98 \pm 0.07$ & $29.9 \pm 0.9$ & $1.18 \pm 0.09$ & $-11.5 \pm 0.4$ & $1.85-10.39$ & 2.9 \\
\hline $2 b$ & $\mathrm{Ce}(\mathrm{III})$ & $12.1 \pm 0.1$ & $19.89 \pm 0.09$ & $24.7 \pm 0.1$ & $26.5 \pm 0.8$ & $1.3 \pm 0.1$ & $-10.2 \pm 0.1$ & $1.85-10.76$ & 2.0 \\
\hline $\begin{array}{l}C_{\mathrm{L}} \\
=10^{-2}\end{array}$ & $\operatorname{Pr}(\mathrm{III})$ & $12.5 \pm 0.1$ & $20.0 \pm 0.1$ & $24.8 \pm 0.1$ & $27.0 \pm 0.9$ & $2.2 \pm 0.1$ & $-9.2 \pm 0.2$ & $1.85-10.52$ & 2.1 \\
\hline \multirow{3}{*}{$\begin{array}{l}C_{\mathrm{M}} \\
=10^{-2}\end{array}$} & $\mathrm{Nd}(\mathrm{III})$ & $12.56 \pm 0.04$ & $20.19 \pm 0.02$ & $24.95 \pm 0.01$ & $27.3 \pm 0.7$ & $1.98 \pm 0.09$ & $-9.5 \pm 0.1$ & $1.84-10.63$ & 2.5 \\
\hline & $\mathrm{Sm}(\mathrm{III})$ & $12.7 \pm 0.1$ & $20.3 \pm 0.1$ & $25.17 \pm 0.04$ & $27.6 \pm 0.9$ & $1.8 \pm 0.2$ & $10.2 \pm 0.1$ & $1.97-11.02$ & 2.5 \\
\hline & $\mathrm{Eu}(\mathrm{III})$ & $11.9 \pm 0.1$ & $19.7 \pm 0.1$ & $24.7 \pm 0.1$ & $27.4 \pm 0.6$ & $1.9 \pm 0.1$ & $-9.5 \pm 0.1$ & $1.81-10.53$ & 2.2 \\
\hline $2 \mathrm{c}$ & $\mathrm{Ce}(\mathrm{III})$ & $12.04 \pm 0.01$ & $19.8 \pm 0.1$ & $24.81 \pm 0.02$ & & $3.2 \pm 0.3$ & $-7.6 \pm 0.1$ & $2.83-10.08$ & 2.2 \\
\hline $\begin{array}{l}C_{\mathrm{L}} \\
=10^{-3}\end{array}$ & $\operatorname{Pr}(\mathrm{III})$ & $11.4 \pm 0.2$ & $19.48 \pm 0.08$ & $24.82 \pm 0.04$ & & $2.9 \pm 0.3$ & $-8.1 \pm 0.2$ & $2.85-10.15$ & 2.6 \\
\hline \multirow{3}{*}{$\begin{array}{l}C_{\mathrm{M}} \\
=10^{-3}\end{array}$} & $\mathrm{Nd}(\mathrm{III})$ & $12.41 \pm 0.05$ & $19.98 \pm 0.05$ & $24.47 \pm 0.09$ & & $3.60 \pm 0.06$ & $-6.5 \pm 0.1$ & $2.88-10.05$ & 1.9 \\
\hline & Sm(III) & $12.62 \pm 0.04$ & $20.11 \pm 0.03$ & $24.42 \pm 0.04$ & & $3.91 \pm 0.04$ & $-6.8 \pm 0.1$ & $3.04-10.29$ & 0.6 \\
\hline & $\mathrm{Eu}(\mathrm{III})$ & $12.2 \pm 0.5$ & $20.0 \pm 0.2$ & $24.4 \pm 0.3$ & & $3.6 \pm 0.6$ & $-6.8 \pm 0.1$ & $2.73-10.09$ & 1.0 \\
\hline
\end{tabular}

Arithmetic mean of $N(\geq 2)$ determinations; negative $z$ values refer to hydroxo species. In Sirko program $R_{\mathrm{f}}$ is the result of a statistical test related to the fit between the experimental and calculated curves.

a The concentration given in the first column are in $\mathrm{mol} \mathrm{dm}^{-3}$.

conditions. At higher $\mathrm{pH}$, the curves of the metal-ligand solutions show a decrease in $\mathrm{pH}$ and a displacement of the equivalent points compared with those of the free ligand, at the same concentrations, which is substantial proof of complexation.

The logarithms of the overall stability constants of the complexes are reported in Table 2. Each value is an average of at least three independent determinations with cation to ligand molar ratio equal to 1 . Higher molar ratio could not be investigated due to precipitation phenomena.

\subsection{Spectrophotometry}

For the ligand substituted by the chromophore $\mathrm{NO}_{2}$, the spectral variation is significantly higher and, therefore, in this section, the variations of especially the ligand $\mathbf{2 b}$ will be studied.

\subsubsection{Acid-base equilibrium}

The principal absorption band of the totally protonated molecule is situated at $325 \mathrm{~nm}(\varepsilon=$ $8070 \mathrm{dm}^{-3} \mathrm{~mol}^{-1} \mathrm{~cm}^{-1}$ ). From $\mathrm{pH} 8$ onward this maximum, which undergoes a shift to $351 \mathrm{~nm}$ diminishes and then splits into two new bands, a low intensity band at $275 \mathrm{~nm}$ and another of high intensity at $446 \mathrm{~nm}$. At higher $\mathrm{pH}$ values, $\mathrm{pH}>$ 10, the pentaanion band corresponding to the totally deprotonated ligand is located at $446 \mathrm{~nm}$ $\left(\varepsilon=21210 \mathrm{dm}^{-3} \mathrm{~mol}^{-1} \mathrm{~cm}^{-1}\right)$.

The numerical interpretation of $(N, L)$ experimental data was done with Sirko $\mathrm{S}$ and/or Letagrop-Spefo programs, where $N$ is the number of solutions studied and $L$, the number of wavelengths. The results obtained for the constants corresponding to the $\mathrm{H}_{x} \mathrm{~L}$ species, $(0 \leq x \leq n$, where $n=5$ for pentaacids) using the two techniques are in good agreement. 


\subsubsection{Complexation studies}

The spectral variation with respect to $\mathrm{pH}$ of solutions of ligand $\mathbf{2} \mathbf{b}$ and different lanthanides $\left(\mathrm{Ce}^{3+}, \mathrm{Pr}^{3+}, \mathrm{Nd}^{3+}, \mathrm{Sm}^{3+}\right.$ and $\left.\mathrm{Eu}^{3+}\right)$ were recorded. The concentration ratio of metal and ligand was maintained at 1 , i.e. $[\mathrm{M}]_{0} /[\mathrm{L}]_{0}=1$. A representative spectra of $\mathbf{2} \mathbf{b}$ with $\mathrm{Eu}^{3+}$ is shown in Fig. 2.

This is characterized by four principal zones of absorption. The first zone is situated between 200 and $280 \mathrm{~nm}$ which is difficult to assign to either ligand or complexes. The region between 280 and 380 results from the deprotonation of the ligand. The variations between 360 and $430 \mathrm{~nm}$ correspond to the formation of complexes. Finally, the intense absorbance between 430 and $500 \mathrm{~nm}$ is due to the totally deprotonated ligand.

Isosbestic points are observed $(275,350,383$, and $408 \mathrm{~nm}$ ), indicating an equilibrium between at least two species. A comparison of these coordinates to those present in the calculated electronic spectra is an additional argument for the choice of the best model.

The logarithm of the overall stability constants calculated with the help of programmes Letagrop and Sirko $\mathrm{S}$ are given in Table 3 . The values are the arithmetic mean of three results.

The program Sirko $\mathrm{S}$ was used in the zone of $\mathrm{pH}<7.5$. It is not surprising, therefore, that in this case the species $\mathrm{MLOH}$ and $\mathrm{ML}(\mathrm{OH})_{2}$ are not detected. This also explains the relatively lower number of solutions $N$ and wavelengths $L$

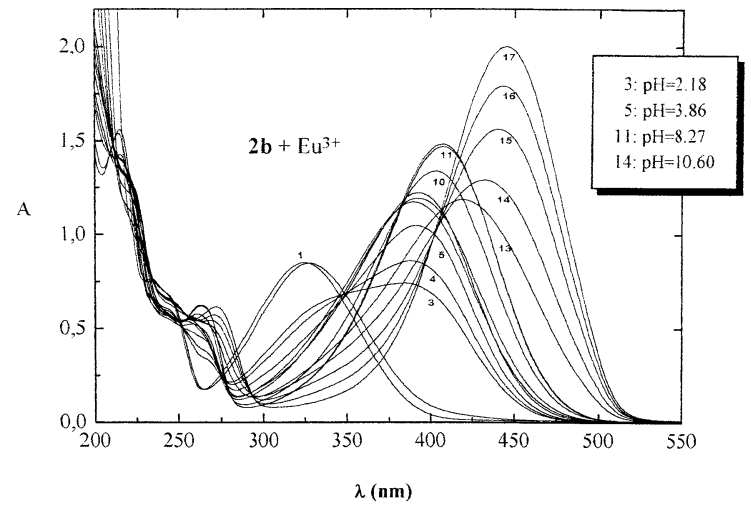

Fig. 2. Experimental UV-visible spectra of the ligand $\mathbf{2 b}$ complexes with $\mathrm{Eu}^{3+}$.

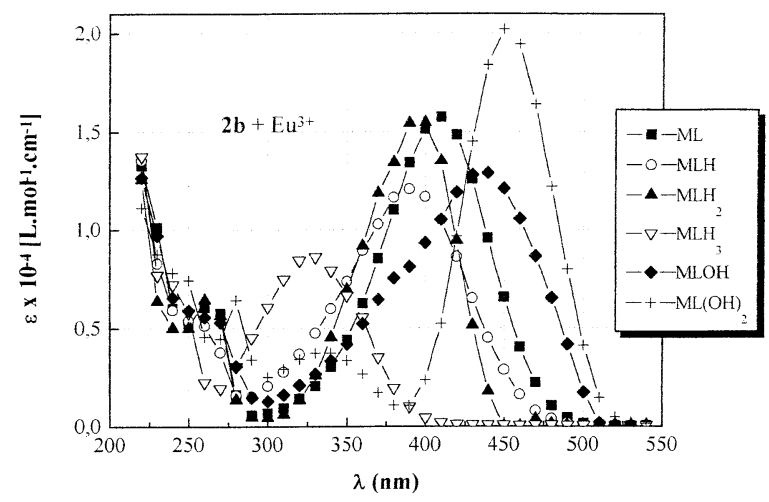

Fig. 3. Calculated electronic spectra of the ligand $\mathbf{2 b}$ complexes with $\mathrm{Eu}^{3+}$.

used for calculation with Sirko S. The constants were used to calculate the specific extinction coefficients which in turn were used to draw the individual electronic spectra. The electronic spectra of complexes of ligand $\mathbf{2} \mathbf{b}$ with $\mathrm{Eu}^{3+}$ are given in Fig. 3.

\section{Discussion}

Under this heading, a comparison will be made with the series of triacids: mono-methylenephosphonic acids (1a, 1b, 1c, 1d and 1e) studied earlier [10].

\subsection{Nature of the complexes formed}

For simplicity, the charges of the complexes will be omitted in the following discussion. If one refers to Table 2, which presents all the results, within the defined $\mathrm{pH}$ range $(2-10)$, several complexes are observed for the pentaacids. An ML complex, a mono-protonated complex MLH a bi-protonated complex $\mathrm{MLH}_{2}$, two anionic complexes $\mathrm{MLOH}$ and $\mathrm{ML}(\mathrm{OH})_{2}$ and a tri-protonated complex $\mathrm{MLH}_{3}$ in the case of $\mathbf{2 a}$ and $\mathbf{2} \mathbf{b}$ but absent with 2c.

\subsection{Order of magnitude of the constants}

The ML complexes of the pentaacids have formation constants of the order of $12 \log , 2$ to $3 \log$ 


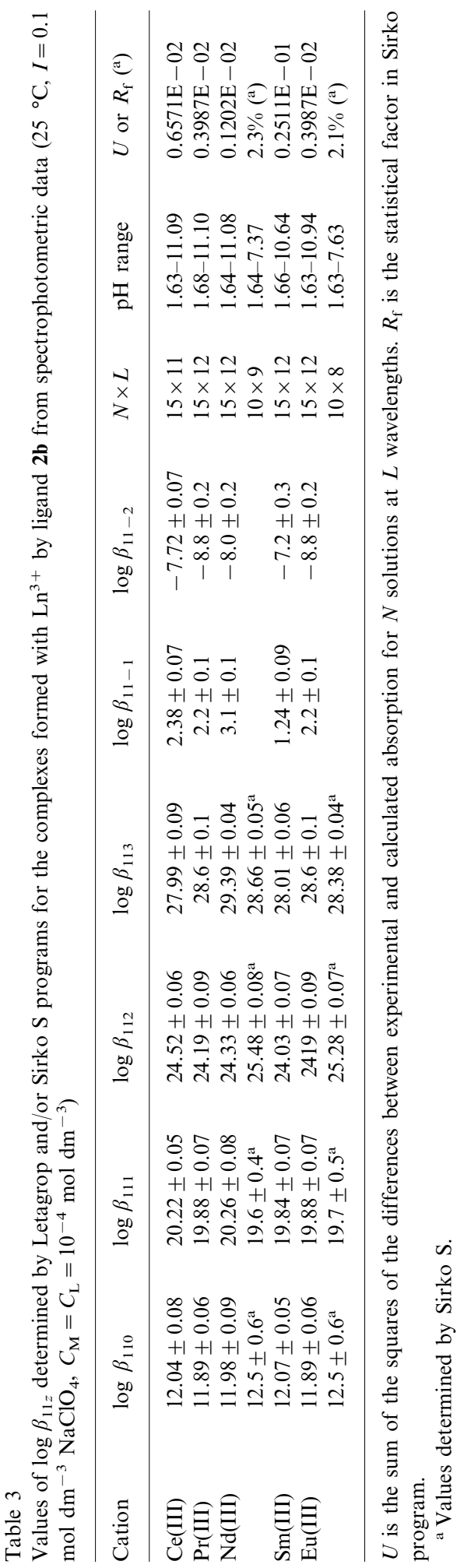


Table 4

Means of stability constants of trivalent lanthanide complexes

\begin{tabular}{|c|c|c|c|c|c|c|}
\hline Ligand & $\log \beta_{113}$ & $\log \beta_{112}$ & $\log \beta_{111}$ & $\log \beta_{110}$ & $\log \beta_{11-1}$ & $\log \beta_{11-2}$ \\
\hline $2 a$ & $29.8^{p}$ & $27.0^{\mathrm{p}}$ & $20.8^{p}$ & $12.0^{\mathrm{p}}$ & $1.2^{\mathrm{p}}$ & $-11.3^{\mathrm{p}}$ \\
\hline \multirow[t]{2}{*}{$2 b$} & $27.1^{p}$ & $24.9^{p}$ & $20.0^{\mathrm{p}}$ & $12.3^{p}$ & $1.8^{\mathrm{p}}$ & $-9.7^{p}$ \\
\hline & $28.5^{\mathrm{s}}$ & $24.5^{\mathrm{s}}$ & $19.9^{\mathrm{s}}$ & $12.1^{\mathrm{s}}$ & $2.2^{\mathrm{s}}$ & $-8.1^{\mathrm{s}}$ \\
\hline $2 c$ & & $24.6^{p}$ & $19.9^{p}$ & $12.2^{\mathrm{p}}$ & $3.4^{\mathrm{p}}$ & $-7.2^{\mathrm{p}}$ \\
\hline
\end{tabular}

p, Potentiometric values; ${ }^{\mathrm{s}}$, spectrophotometric values.

$\mathrm{U}$ higher than for the corresponding triacid complexes [10]. This fact may perhaps be attributed to a charge effect, as ML is a neutral complex for the triacids and a dianionic one for the pentaacids. A similar effect has been observed by P. Schwinte [17] concerning the lanthanide complexes of calixarenes substituted at the $-\mathrm{OH}$ position by carboxylic acid groups. Table 4 gives the average $\log \beta_{111}$ for the pentaacids as 20.2 , and the average values of the first stepwise protonation constants are equal to $8.8 \log \mathrm{U}$ for $\mathbf{2 a}, 7.6$ for $\mathbf{2 b}$ and 7.8 for $\mathbf{2 c}$. The average $\log \beta_{112}$ value is 25.5 , and the average second stepwise protonation constants for $\mathrm{MLH}$ to $\mathrm{MLH}_{2}$ is $6.2 \log \mathrm{U}$ for $\mathbf{2 a}$, 4.9 for $\mathbf{2 b}$ and 4.7 for $\mathbf{2 c}$. These values are similar to those of the first protonation constants of the triacid complexes, therefore, it is likely that this second protonation of the pentaacids complexes occurs at the second phosphonate group, and that the complex $\mathrm{MLH}_{2}$ is protonated once on each of the phosphonate sites. Finally, the average $\log \beta_{113}$ value is 28.5 , and the third stepwise protonation constant of $\mathrm{MLH}_{2}$ to $\mathrm{MLH}_{3}$ is 2.8 for the complexes of $\mathbf{2} \mathbf{a}$ and 2.3 for those of $\mathbf{2} \mathbf{b}$ (in $\log$ $\mathrm{U})$. These values are clearly weaker than the second protonation constants of the triacid complexes. The stepwise protonation constants of the complexes of $\mathbf{2 a}$ are all greater than those of $\mathbf{2 b}$ or 2c, which is due to the donor inductive effect of the methyl substituent which favors the liberation of the proton.

\subsection{Distribution curves of the complexes}

With the values of $\log \beta_{11 z}$ and with the aid of the Haltafall program, the extent of formation of each species in the chosen model is calculated. The distribution of europium(III) complexes with ligand $\mathbf{2 b}$ is represented in Fig. 4. For all other ligands, the distribution of the complexes is quite well balanced within the $\mathrm{pH}$ range considered.

\subsection{Selectivity of complexation in the lanthanide series}

The complexing selectivity $S\left(\mathrm{M} / \mathrm{M}^{\prime}\right)$ of a cation $M$ with respect to another cation $\mathbf{M}^{\prime}$, is defined, as the logarithm of the ratio of the stability constants of the ML and M'L complexes. A good selectivity of 26 and 25 is observed for $\mathrm{Sm}^{3+} /$ $\mathrm{Ce}^{3+}$ with, respectively, 1d and 2a. These ligands are characterized by a methyl group in the para position.

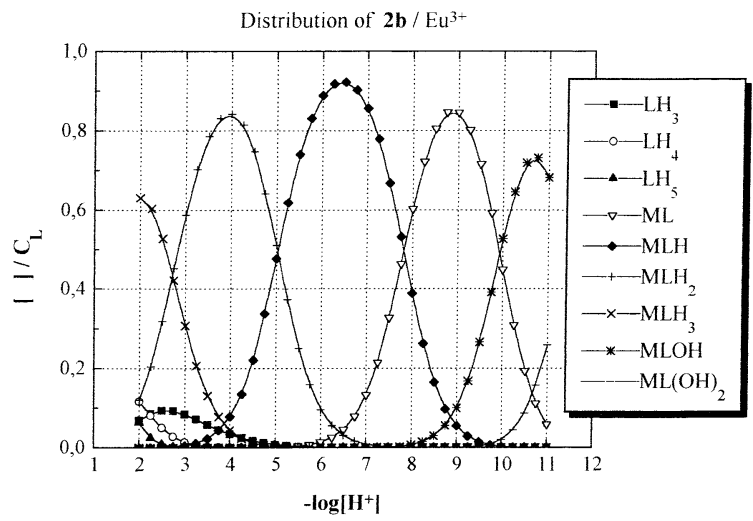

Fig. 4. Distribution curves of the complexes of the ligand $\mathbf{2 b}$ with $\mathrm{Eu}^{3+}$. 


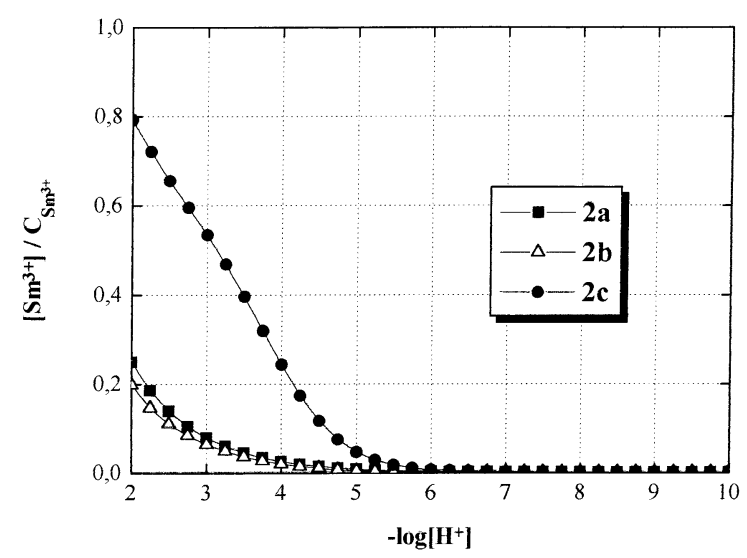

Fig. 5. Fraction of calculated free $\mathrm{Sm}^{3+}$ concentration vs. $-\log \left[\mathrm{H}^{+}\right]$, for the ligands studied $\left(C_{\mathrm{M}}=C_{\mathrm{L}}=10^{-2} \mathrm{~mol}\right.$ $\left.\mathrm{dm}^{-3}\right)$.

\subsection{Scaling of the complexing ability of the ligands}

The percentages of free $\mathrm{Sm}^{3+}$ are calculated as a function of- $\log \left[\mathrm{H}^{+}\right]$for the different ligands at $C_{\mathrm{M}}=C_{\mathrm{L}}=10^{-2} \mathrm{~mol} \mathrm{dm}^{-3}$. This is illustrated in Fig. 5. An examination of the figure clearly shows that the complexing power $\left(\beta_{110}\right)$ of the pentaacids is in the proposed relative order, $\mathbf{2 c}<$ $\mathbf{2 b}=\mathbf{2 a}$. Hence, for both sequences, triacids as reported earlier, and pentaacids as in this work, the acid having the methyl group at the para position with respect to the phenolic $\mathrm{OH}$ has the greatest complexing power.

\subsection{Comparison with the complexation of alkaline-earth cations}

The alkaline-earth and lanthanide cations have in common the property of forming essentially electrostatic interactions with their ligands and it is interesting to compare the $\mathrm{Ca}^{2+}$ and $\mathrm{Eu}^{3+}$ complexes, as these cations have the same ionic radius [18]. It is, therefore, possible to examine the influence of the cationic charge.

S. Chafaâ [19] studied, the complexes of 1a, 1c and $\mathbf{2 b}$ with calcium under similar experimental conditions as in this work. With that ligands, he identified, respectively, the ML and MLH complexes, the ML, MLH and $\mathrm{MLH}_{2}$ complexes, the ML, MLH, $\mathrm{MLH}_{2}$ and $\mathrm{MLH}_{3}$ complexes. The hydroxide complexes were not taken into account in his study. The $\log \beta_{x y z}$ constants of the calcium complexes are reported in Table 5 together with the values for the europium.

If one takes into account the fact that there is no evidence of any sodium complex formation under the same experimental conditions even though $\mathrm{Na}^{+}$has the same ionic radius as $\mathrm{Ca}^{2+}$ and $\mathrm{Eu}^{3+}$, it can be concluded that for equally sized cations, the stability of the ML complexes increases strongly as a function of cation charge (6-7 $\log U)$. The same conclusion is reached for the protonated complexes. It is for this reason that the most protonated complexes can be observed with europium, but never with calcium.

\subsection{Comparison with the complexation of $3 d$ metal cations}

The values for the $\log \beta_{110}$ constants of the $3 \mathrm{~d}$ metals cations $\mathrm{Ni}^{2+}, \mathrm{Cu}^{2+}$ and $\mathrm{Zn}^{2+}$ have also been determined by Chafaa et al. [20], and again the eventual presence of hydroxide species within the $\mathrm{pH}$ range studied was not taken into account.

Table 5

Values of $\log \beta_{11 z}$ of calcium(II) and europium(III) complexes

\begin{tabular}{|c|c|c|c|c|c|c|c|c|}
\hline \multirow[t]{2}{*}{ Ligand } & \multicolumn{2}{|c|}{$\log \beta_{110}$} & \multicolumn{2}{|c|}{$\log \beta_{111}$} & \multicolumn{2}{|c|}{$\log \beta_{112}$} & \multicolumn{2}{|c|}{$\log \beta_{113}$} \\
\hline & $\mathrm{Ca}^{2+}$ & $\mathrm{Eu}^{3+}$ & $\mathrm{Ca}^{2+}$ & $\mathrm{Eu}^{3+}$ & $\mathrm{Ca}^{2+}$ & $\mathrm{Eu}^{3+}$ & $\mathrm{Ca}^{2+}$ & $\mathrm{Eu}^{3+}$ \\
\hline 1a & 2.9 & 10.6 & 13.4 & 16.9 & & 20.6 & & \\
\hline $1 \mathrm{c}$ & 3.4 & 9.1 & 12.0 & 14.1 & 17.8 & & & \\
\hline $2 b$ & 5.9 & 11.9 & 14.0 & 19.7 & 20.9 & 24.7 & 25.7 & 27.4 \\
\hline
\end{tabular}

The columns of $\mathrm{Eu}^{3+}$ with $\mathbf{2 b}$ is this work while with $\mathbf{1 a}$ and $\mathbf{1} \mathbf{c}$ is our work to be submitted ([10]). The other values are from [9]. 
Table 6

Values of $\log \beta_{110}$ of transition cations $\mathrm{Ni}^{2+}, \mathrm{Cu}^{2+}, \mathrm{Zn}^{2+}$ and $\mathrm{Eu}^{3+}$

\begin{tabular}{lllll}
\hline Ligand & $\mathrm{Ni}^{2+}$ & $\mathrm{Cu}^{2+}$ & $\mathrm{Zn}^{2+}$ & $\mathrm{Eu}^{3+}$ \\
\hline $\mathbf{1 a}$ & $5.2[9]$ & $11.5[9]$ & & $10.6[10]$ \\
$\mathbf{1 c}$ & $5.9[9]$ & $10.4[9]$ & & $9.11[10]$ \\
$\mathbf{2 b}$ & 6.5 & 11.8 & 9.8 & 11.9 \\
\hline
\end{tabular}

The results are reported in Table 6 and compared with those for $\mathrm{Eu}^{3+}$ determined in this study.

It is evident that the $\mathrm{Cu}^{2+}$ complexes are slightly stronger than those of $\mathrm{Eu}^{3+}$, whereas the $\mathrm{Ni}^{2}+$ complexes are clearly weaker than those of $\mathrm{Eu}^{3+}$ (a difference of $5 \log \mathrm{U}$ ). This is regardless of the ligand considered and is not surprising as this agrees with the Irving-Williams order of stabilities, recently confirmed for different systems with the $3 \mathrm{~d}$ transition metals [21].

\section{References}

[1] V. Böhmer, W. Vogt, S. Chafaa, J. Meullemeestre, M.J. Schwing, F. Vierling, Helv. Chim. Acta 76 (1993) 1425.

[2] L. Cecille, M. Casarci, L. Pietrelli (Eds.), New Separation Chemistry Techniques for Radioactive Wastes and Other Specific Applications, Elsevier, London, 1991.

[3] O. Jacquin, S. Faux-Mallet, G. Gote, D. Bauer, in: P.A. Williams, M.J. Hudson (Eds.), Recent Developments in Ion Exchange, Elsevier, London, 1987, p. 213.
[4] L.I. Tikhinova, Russian J. Inorg. Chem. 10 (1) (1965) 70.

[5] G.S. Tereshin, O.B. Kuznetsova, Koord. Khim. 11 (5) (1979) 1639.

[6] F. Suran, H. Yenfung, W. Xiaomay, L. Lemin, X. Kwangxian, Ziran Kexueban 6 (1984) 73.

[7] S. Sujatha, M.L.P. Reddy, T.R. Ramamohan, A.D. Damodaran, J. Radioanal. Nuclear Chem. 174 (1993) 271.

[8] J.M. Wagener, N.V. Jarvis, South African J. Chem. 48 (1995) 85.

[9] F. Benghanem, S. Chafaa, G.M. Bouet, M.A. Khan, Phosphorus Sulfur Silicon Relat. Elem. 170 (2001) 159.

[10] E. Bentouhami, G.M. Bouet, M.A. Khan, Talanta, submitted.

[11] V. Böhmer, W. Vogt, S. Chafaa, J. Meullemeestre, M.J. Schwing, F. Vierling, Helv. Chim. Acta 76 (1993) 139.

[12] E. Merck, Methodes d'Analyses Complexometriques par les Titriplex Darmstadt, Germany, 1964.

[13] V.I. Vetrogon, N.G. Lukyanenko, M.J. Schwing-Weill, F. Arnaud-Neu, Talanta 41 (1994) 2105.

[14] P. Gans, A. Sabatini, A. Vacca, J. Chem. Soc., Dalton Trans. (1985) 1195.

[15] J. Ameziane, M. Aplincourt, J.C. Pierrard, J. Chem. Research (S), (1995) 320.

[16] L.G. Sillen, B. Warnqvist, Ark. Kemi. 31 (1968) 377.

[17] F. Arnaud-Neu, S. Cremin, S. Harris, M. Anthony Mc Kervey, M.J. Schwing-Weill, P. Schwinté, A. Walker, J. Chem. Soc., Dalton Trans. (1997) 329.

[18] R.D. Shannon, Acta Cryst. A32 (1976) 751.

[19] S. Chafaa, Doctoral thesis, Université Louis Pasteur Strasbourg (1993).

[20] M.J. Schwing-Weill, S. Chafaa, J. Meullemeestre, F. Vierling, J. Chem. Research (S), (1995) 258.

[21] M.A. Khan, G. Bouet, F. Vierling, J. Meullemeestre, M.J. Schwing, Trans. Met.Chem. 21 (1996) 231. 